\title{
O PRINCIPIO DA EFICIÊNCIA E A EFETIVA PRESTAÇÃO DO TRANSPORTE ESCOLAR NAS ZONAS RURAIS DE MANAUS/AM
}

\author{
Fernando Prestes ${ }^{1}$ \\ Valmir César Pozzetti ${ }^{2}$
}

\begin{abstract}
RESUMO
A região amazõnica é uma região sui generis: ora muita chuva, ora falta de chuva. O objetivo desta pesquisa é analisar a importância do transporte escolar nas zonas rurais do municipio de Manaus/AM, como garantia do acesso à escola, tendo como parâmetro o dever do Estado de propiciar o transporte, única forma de acesso à escola nessa distante e isolada região do país. Conclui-se que o Poder público não vem cumprindo com seu dever estabelecido na Constituição Federal. A metodologia utilizada nessa pesquisa é a do método dedutivo e, quanto aos meios é bibliografica, quanto aos fins é qualitativa.
\end{abstract}

PALAVRAS-CHAVE: Transporte Escolar Rural; Principio da Eficiência; Dever do Estado; Cidadania; Direito fundamental.

\section{THE PRINCIPLE OF EFFICIENCY AND THE EFFECTIVE PROVISION OF SCHOOL TRANSPORT IN RURAL AREAS OF MANAUS/AM}

\begin{abstract}
The amazõnica region is a sui generis region: lots of rain, well lack of rain. The objective of this research is to analyze the importance of school transport in rural areas of the municipality of Manaus/AM, as a guarantee of access to school, having as parameter the duty of the State to provide transportation, only way of access to school in this remote and isolated area of the country. It is concluded that the Government does not come with your duty established in the Federal Constitution. The methodology used in this research is the deductive method and bibliographic and qualitative.
\end{abstract}

KEYWORDS: Rural School Transportation; Principle of Efficiency; The duty of the State; Citizenship; fundamental right.

\section{INTRODUÇÃO}

A região amazõnica é cortada por rios caudalosos e inumeros igarapés. O rio além de ser a vida, é o meio de transporte na regiao devido a quase inexistência de

\footnotetext{
${ }^{1}$ Bacharel em Direito pela Universidade Federal do Amazonas (1998) e Pós-graduado em Processo Civil pela Universidade Federal do Amazonas (1999). Defensor Público concursado no Estado do Amazonas. Mestrando em Direito Ambiental pela Universidade do Estado do Amazonas, Ingresso Turma 2017. Pesquisador do Núcleo de Estudos e Pesquisas de Políticas Socioambientais da Amazônia - UEA/PPGDA.

${ }^{2}$ Doutor em Biodireito/Direito Ambiental pela Université de Limoges/França (título revalidado pela Univ. Federal de Pernambuco). Mestre em Direito do Urbanismo e do Meio Ambiente, pela Université de Limoges, França (título revalidado pela Universidade Luterana do Brasil).
} 
estrada; uma vez que em determinada época do ano, a chuva é constante, alagando as poucas estradas e as destruindo, e um outra época, a seca provoca a baixa das águas, inviabilizando o transporte.

Dessa forma, o Estado deve desenvolver politicas públicas que se compatibilizem com as estações da região, no sentido de tornar possivel o acesso de crianças e professores, à escola, em especial as escolas rurais, frequentada por centenas de alunos ao longo das margesn dos rios.

A problematica que se estabelece nesta pesquisa é : diante das peculiaridades da região amazônica, de que forma o Estado poderá garantir, a qualquer tempo, tranporte eficiente e de qualidade a essas crianças que tem o Direito Constitucional garantido, do acesso à escola ?

O objetivo desta Pesquisa é o estudo do princípio constitucional da eficiência e a efetiva prestação do transporte escolar nas zonas rurais, no qual será analisado a prestação do transporte das escolas rurais para estudantes, professores e pesquisadores, que necessitam deste meio de transporte para freqüentar e trabalhar em escolas da zona rural.

A justificativa para essa Pesquisa encontra razão no fato de que crianças da zona rural não conseguem completar o ciclo escolar de forma normal; todo ano, com as cheias e vazantes, as crianças sofrem o prejuízo de não haver trasnporte, ficando isoladas e, em consequencia, atrasando seu desenvolvimento intelectual

Pretende-se, então, analisar o transporte de estudantes oferecido nas zonas rurais, da cidade de Manaus pela Administração Pública, através de dois programas Governamentais: o Caminho da Escola e o Programa Nacional de Apoio ao Transporte do Escolar, posto que ambos visam atender aos alunos que residem na zona rural.

O transporte escolar ganha uma importância vital para que se consiga ter acesso à escola, pois sem este serviço, na Região Amazônica, os alunos não tem acesso ao ensino, daí porque a importância de se analisar se o mesmo é ofertado com eficiência, levando em consideração as distâncias percorridas entre a casa e a escola e a regularidade na prestação do serviço, bem como a análise da atuação dos servidores públicos e do cumprimento do princípio da eficiência, expresso na Constituição Federal, como garantia de cidadania e acesso à escola, especialmente nas zonas rurais. 
A metodologia que será utilizada nesta Pesquisa é a do método dedutivo, sendo que, quanto aos meios será utilizada a Pesquisa bibliográfica - com uso da doutrina, legislação e jurisprudência - e quanto aos fins a Pesquisa será qualitativa.

\section{O TRANSPORTE ESCOLAR NAS ZONAS RURAIS}

O transporte escolar nada mais é que a logistica a ser utilizada para levar e trazer o estudante de casa para escola e da escola para casa. É um Direito da criança e deve ser cumprido pelo Estado, sob pena de abandon intellectual.

A Constituição Federal de 1988 (arts. 208 e 211), garante às pessoas em idade escolar o acesso e a permanência a tais instituições, devendo o Estado promover todas as ações suplementares para efetivação dessa políticas pública em prol dos estudantes e Professores, onde quer que eles se encontrem, especialmente nas escolas rurais.

Apenas assegurar as vagas não é o suficiente para os indivíduos terem acesso ao ensino, torna-se fundamental ofertar o transporte escolar para as crianças e adolescentes, conforme prevê a Carta maior $(\mathrm{CF} / 88)$ :

Art. 208. O dever do Estado com a educação será efetivado mediante a garantia de:

I - ensino fundamental obrigatório e gratuito, assegurada, inclusive, sua oferta gratuita para todos os que a ele não tiveram acesso na idade própria;

II - progressiva universalização do ensino médio gratuito;

III - atendimento educacional especializado aos portadores de deficiência, preferencialmente na rede regular de ensino;

IV - atendimento em creche e pré-escola às crianças de zero a seis anos de idade;

$\mathrm{V}$ - acesso aos níveis mais elevados do ensino, da pesquisa e da criação artística, segundo a capacidade de cada um;

VI - oferta de ensino noturno regular, adequado às condições do educando;

VII - atendimento ao educando, no ensino fundamental, através de programas suplementares de material didático-escolar, transporte, alimentação e assistência à saúde.

$\S 1^{\circ}$ - O acesso ao ensino obrigatório e gratuito é direito público subjetivo (gn)

Percebe-se que é dever do Estado garantir e efetivar a educação e, dentre os requisitos para se efetivar a educação, está a oferta de transporte.

No tocante ao ensino fundamental a $\mathrm{CF} / 88$ estabelece que este é um dever dos Municipios :

Art. 211. A União, os Estados, o Distrito Federal e os Municípios organizarão em regime de colaboração seus sistemas de ensino. 
$\S 1^{\circ}$ A União organizará o sistema federal de ensino e o dos Territórios, financiará as instituições de ensino públicas federais e exercerá, em matéria educacional, função redistributiva e supletiva, de forma a garantir equalização de oportunidades educacionais e padrão mínimo de qualidade do ensino mediante assistência técnica e financeira aos Estados, ao Distrito Federal e aos Municípios.

$\S 2^{\circ}$ Os Municípios atuarão prioritariamente no ensino fundamental e na educação infantil. (gn)

Assim, é importante frisar que, como a região Amazônica tem algumas peculiaridades climáticas em decorrência dos regimes das chuvas e dos rios, que alteram o volume das águas, dificultamndo a navegabilidade, destrõem as estradas rurais, em razão de atoleiros, prejudicando as condições de trafegar os veículos, é necessário encontrar uma solução para essa problemática; uma vez que esses estudantes rurais são "sujeitos de direit".

As dificuldades de logísticas são constantemente enfrentadas; pois as vezes o transporte até existe, mas a falta de infraestrutura da região impossibilita o trânsito dos veículos e lanchas que, em conseqüência, impedem o fluxo dos estudantes até as instituições de ensino.

Quando se considera todas as dificuldades que muitas vezes estes estudantes rurais enfrentam para chegar à sala de aula, fica claro que existe uma incoerência com que estabelece a Lei n ${ }^{\circ}$ 9.394, de 1996 - Diretrizes e bases da Educação Nacional :

Art. 11. Os Municípios incumbir-se-ão de:

I - organizar, manter e desenvolver os órgãos e instituições oficiais de ensino, integrando-as às políticas e planos educacionais da União e dos Estados;

II - exercer ação redistributiva em relação às suas escolas;

III - baixar normas complementares para o seu sistema de ensino;

IV - autorizar, credenciar e supervisionar os estabelecimentos do seu sistema de ensino;

V - oferecer a educação infantil em creches e pré-escolas, e, com prioridade, o ensino fundamental, permitida a atuação em outros níveis de ensino somente quando estiverem atendidas plenamente as necessidades de sua área de competência e com recursos acima dos percentuais mínimos vinculados pela Constituição Federal à manutenção e desenvolvimento do ensino.

VI - assumir o transporte escolar dos alunos na rede municipal. (incluído pela Lei $n^{\circ} 10.709$, de 31.7.2003) (grifado)

E a Lei $n^{\circ}$ 9.394/96 vai mais além :

Art. $3^{\circ} \mathrm{O}$ ensino será ministrado com base nos seguintes princípios:

I - igualdade de condições para o acesso e permanência na escola;

II - liberdade de aprender, ensinar, pesquisar e divulgar a cultura, o pensamento, a arte e o saber; 
III - pluralismo de idéias e de concepções pedagógicas;

IV - respeito à liberdade e apreço à tolerância;

$\mathrm{V}$ - coexistência de instituições públicas e privadas de ensino;

VI - gratuidade do ensino público em estabelecimentos oficiais;

VII - valorização do profissional da educação escolar;

VIII - gestão democrática do ensino público, na forma desta Lei e da legislação dos sistemas de ensino;

IX - garantia de padrão de qualidade;

$X$ - valorização da experiência extra-escolar;

XI - vinculação entre a educação escolar, o trabalho e as práticas sociais.

XII - consideração com a diversidade étnico-racial. (gn)

Verifica-se que a lei garante o ensino em igauldade de condições. Dessa forma, o Poder Público é responsavel para garantir aos estudantes da zona rural, igualdade de condições para o aprendizado.

Se compararmos a disponibilidade de acesso da população estudantil camponesa e a urbana, às escolas, veremos que os educandos da cidade têm maior acessibilidade, pois estão mais próximos da instituição, contam com estradas e ruas melhores, existência de transporte público e vias em melhor condição de trafegar. Assim, como consequência a igualdade de condições de acesso e permanência na escola é diferente para os estudantes urbanos.

O transporte escolar é um dever do Estado por ser a garantia de acesso e permanência do educando no ambiente escolar.

Só para ilustrar, é preciso distinguir o transporte escolar rural do urbano: o transporte pode ser urbano ou rural, público ou privado; sendo este último praticado somente no meio urbano, visto que nas áreas rurais este serviço não é viável devido aos altos custos operacionais proporcionados pela carência de população e das más condições das estradas.

A zona rural é o espaço compreendido no meio agrícola, é uma região não urbanizada, não compreendida pelas cidades, destinada as atividades da agricultura, pecuária, sivicultura, suinocultura, extrativismo e conservação ambiental; ou seja, onde se desenvolvem basicamente atividades do setor primário.

Ao se analisar as dificuldades que os moradores da área rural têm em se deslocar de uma área para outra, evidencia-se a importância do transporte escolar no seu dia a dia. A falta de estradas adequadas para se locomover, ou a existência de estradas sem condições de uso, tem trazido muitos transtornos aos discentes do meio 
rural, tendo como consequência uma baixa qualidade no seu processo de ensino, aprendizado e a pior a realidade : a da evasão escolar.

A área rural tem importância estratégica pois é neste ambiente que se produz grande parte dos alimentos e matérias-primas consumidos no espaço urbano, onde vivem os agricultores e seus familiares, que geralmente moram em prédio rústicos, plantando e colhendo para seu consumo e/ou para venda do excedente, necessitando de assistência técnica e de serviços públicos como: escola, posto de saúde e previdência, a fim de se manterem no campo e não migrarem para as cidades.

A escola no campo é um dos fatores decisivos para a permanência do agricultor e sua família na zona rural e a oferta de transporte escolar um serviço essencial que garante o acesso dos alunos nas escolas, evitando a evasão escolar que pode ocorrer pela inexistência de transporte público ou pela falta de meios e recursos para arcar com os custos do deslocamento.

O transporte escolar no campo está previsto na legislação infraconstitucionais e na Lei Federal $n^{\circ}$. 9.394/96, ao garantir, em linhas gerais o acesso de alunos e Professores da área rural as escolas do ensino fundamental e médio nos seus respectivos núcleos populacionais.

A grande maioria dos moradores das zonas rurais não possuem condições financeiras e dependem exclusivamente de Políticas Públicas, tais como : postos de saúde, escolas pública e transporte escolar. No tocante às Políticas Públicas de trasnporte escolar, existem atualmente dois programas voltados ao transporte de estudantes: o Caminho da Escola e o Programa Nacional de Apoio ao Transporte do Escolar ambos visam atender alunos da zona rural.

O Caminho da Escola foi criado pela Resolução no 3, de 28 de março de 2007, e consiste na concessão, pelo Banco Nacional de Desenvolvimento Econômico e Social (BNDES), de linha de crédito especial para a aquisição, pelos estados e municípios, de ônibus, miniônibus ou micro-ônibus e de embarcações novas.

O segundo programa governamental é o Programa Nacional de Apoio ao Transporte do Escolar instituído pela Lei n ${ }^{\circ} 10.880 / 2004$, com o objetivo de garantir o acesso e a permanência nos estabelecimentos escolares dos alunos do ensino fundamental público residentes em área rural que utilizem transporte escolar, por meio 
de assistência financeira, em caráter suplementar, aos estados, Distrito Federal e municípios.

Este programa consiste na transferência automática de recursos financeiros, sem necessidade de convênio ou outro instrumento congênere, para custear despesas com reforma, seguros, licenciamento, impostos e taxas, pneus, câmaras, serviços de mecânica em freio, suspensão, câmbio, motor, elétrica e funilaria, recuperação de assentos, combustível e lubrificantes do veículo ou da embarcação utilizada para o transporte de alunos da educação básica pública residentes em área rural, ou para o pagamento de serviços contratados junto a terceiros para o transporte escolar.

\section{O DEVER CONSTITUCIONAL DE ACESSO A EDUCAÇÃO}

A Constituição Federal brasileira de 1988 trata da educação elevando-a a categoria de princípio para o desenvolvimento da sociedade brasileira, indicando, como objetivo precípuo, o pleno desenvolvimento da pessoa, seu preparo para o exercício da cidadania e sua qualificação para o trabalho, sendo dever do Estado o desenvolvimento do ensino, a promoção de ações que assegurem a igualdade de condições para o acesso e a permanência do aluno na escola:

Art. 205. A educação, direito de todos e dever do Estado e da família, será promovida e incentivada com a colaboração da sociedade, visando ao pleno desenvolvimento da pessoa, seu preparo para o exercício da cidadania e sua qualificação para o trabalho. (gn)

Art. 206. O ensino será ministrado com base nos seguintes princípios:

I - igualdade de condições para o acesso e permanência na escola;

II - liberdade de aprender, ensinar, pesquisar e divulgar o pensamento, a arte e o saber;

III - pluralismo de idéias e de concepções pedagógicas, e coexistência de instituições públicas e privadas de ensino;

IV - gratuidade do ensino público em estabelecimentos oficiais;

V - valorização dos profissionais do ensino, garantido, na forma da lei, plano de carreira para o magistério público, com piso salarial profissional e ingresso exclusivamente por concurso público de provas e títulos, assegurado regime jurídico único para todas as instituições mantidas pela União;

VI - gestão democrática do ensino público, na forma da lei;

VII - garantia de padrão de qualidade. (gn)

No tocante à igualdade de condições vê-se que a criança da zona rural jamais terá as mesmas oportunidades que as das zonas urbanas. 
O contexto social brasileiro é permeado pela desigualdade e pela falta de oportunidades ao exercício de muitos dos direitos fundamentais do cidadão. Esta realidade, por vezes, é tão forte que a simples disponibilização do ensino público e gratuito não é suficiente para assegurar o acesso e a permanência da criança e do jovem na escola.

O educando, em especial o mais carente e o que reside no campo, possui inúmeras dificuldades para manter-se na escola, tais como: material didático-escolar, transporte, alimentação e assistência à saúde; assim, o legislador constituinte atrelou ao dever de oferecer a educação, outras obrigações que se podem chamar de acessórias ou suplementares, mas que, na verdade, complementam o direito ao ensino público e por meio das quais se possibilita o acesso e a permanência do educando no ambiente escolar.

O artigo 208 da Constituição Federal trata das garantias aos educandos, cuja finalidade é o efetivo exercício do direito à educação, estando, entre estas, o transporte escolar:

Art. 208. O dever do Estado com a educação será efetivado mediante a garantia de: I - ensino fundamental obrigatório e gratuito, assegurada, inclusive, sua oferta gratuita para todos os que a ele não tiveram acesso na idade própria;

II - progressiva universalização do ensino médio gratuito;

III - atendimento educacional especializado aos portadores de deficiência, preferencialmente na rede regular de ensino;

IV - educação infantil, em creche e pré-escola às crianças até 5 (cinco) anos de idade;

$\mathrm{V}$ - acesso aos níveis mais elevados do ensino, da pesquisa e da criação artística, segundo a capacidade de cada um;

VI - oferta de ensino noturno regular, adequado às condições do educando;

VII - atendimento ao educando, no ensino fundamental, através de programas suplementares de material didático-escolar, transporte, alimentação e assistência à saúde.

$\S 1^{\circ}$ - $\mathrm{O}$ acesso ao ensino obrigatório e gratuito é direito público subjetivo $\S 2^{\circ}$ - O não oferecimento do ensino obrigatório pelo Poder Público, ou sua oferta irregular, importa responsabilidade da autoridade competente. (gn)

Vê-se que a Constituição Federal indica expressamente que a manutenção de programas suplementares destina-se ao ensino fundamental, o que poderia conduzir à interpretação literal de que os alunos da educação infantil e do ensino médio não fariam jus a tal garantia.

A Constituição Federal define qual o nível de ensino em que cada ente da Federação deve atuar prioritariamente: 
Art. 211. A União, os Estados, o Distrito Federal e os Municípios organizarão em regime de colaboração seus sistemas de ensino.

$\S 1^{\circ}$ A União organizará o sistema federal de ensino e o dos Territórios, financiará as instituições de ensino públicas federais e exercerá, em matéria educacional, função redistributiva e supletiva, de forma a garantir equalização de oportunidades educacionais e padrão mínimo de qualidade do ensino mediante assistência técnica e financeira aos Estados, ao Distrito Federal e aos Municípios.

$\S 2^{\circ}$ Os Municípios atuarão prioritariamente no ensino fundamental e na educação infantil.

$\S 3^{\circ}$. Os Estados e o Distrito Federal atuarão prioritariamente no ensino fundamental e médio.

$\S 4^{\circ}$. Na organização de seus sistemas de ensino, os Estados e os Municípios definirão formas de colaboração, de modo a assegurar a universalização do ensino obrigatório;

$\S 5^{\circ}$ A educação básica atenderá prioritariamente ao ensino regular. relacionados

Ao oferecer a educação infantil e o ensino médio, o Poder Público também se obriga a desenvolver o programa de transporte para os alunos destas etapas escolares, o recente inciso VI, introduzido no art. 11 da LDB, pela Lei Federal $n^{\circ}$ 10.709/2003, deixa claro a responsabilidade do Município no transporte escolar, qual seja, de transportar os alunos matriculados em sua rede ensino, isto é, nas escolas Municipais.

Cabe esclarecer que o legislador delimitou as responsabilidades de cada ente em oferecer o transporte escolar aos respectivos alunos, assim a responsabilidade pelo transporte escolar, envolvendo alunos matriculados em escolas estaduais é do Estado, nos termos do que dispõe o art. 10, inc VII, da Lei n ${ }^{\circ}$ 9.394/96, ou seja, um dever compartilhado :

Art. 10. Os Estados incumbir-se-ão de:

(...) omissis

VI - assumir o transporte escolar dos alunos da rede estadual. (gn)

Portanto, está delimitada a responsabilidade de cada um dos entes, embora algumas decisões do Poder Judiciário ainda sejam no sentido da responsabilização solidária entre Estado e Municípios. Mesmo com a definição trazida pela Lei $\mathrm{n}^{\circ}$ 10.709/03, algumas decisões entendem pela responsabilidade do Município em relação ao transporte dos alunos da rede estadual.

O transporte escolar ja foi objeto de ações judiciais, sendo o entendimento do Poder Judiciário, nas diversas demandas intentadas contra o Poder Público, no sentido de que o transporte escolar é uma garantia do educando matriculado em escola 
pública de educação básica, independentemente do nível ou etapa escolar em que se encontra.

A responsabilidade da Administração Municipal, nesse sentido, seria de cooperar e manter parceria com o Estado para a realização do transporte. Com a edição da Lei no 10.709/03 e da definição por ela trazida, já se encontram decisões judiciais, no sentido de reconhecer que o Município não é responsável pelo transporte dos alunos da rede estadual. Vejamos as decisões judiciais :

\begin{abstract}
APELAÇÃO CÍVEL. MANDADO DE SEGURANÇA. TRANSPORTE ESCOLAR MUNICIPAL. Inexiste omissão do Poder Executivo Municipal no oferecimento de transporte escolar gratuito a alunos da rede Estadual de ensino, uma vez ausente convênio com o Estado, nos termos do disposto no art. 62, inciso I, da Lei de Responsabilidade Fiscal, LC 101/00. APELAÇÃO DESPROVIDA. (Apelação Cível No 70010141653, Décima Primeira Câmara Cível, Tribunal de Justiça do RS, Relator: Antônio Maria Rodrigues de Freitas Iserhard, Julgado em 24/11/2004)

AÇÃO CIVIL PÚBLICA. TRANSPORTE ESCOLAR. ALUNOS DA REDE PÚBLICA. A alteração da LDB, pela Lei 10709/2003, não deixa mais dúvida quanto à responsabilidade de estados e municípios em prover o transporte escolar dos alunos matriculados nas suas respectivas redes de ensino, cristalizando direito subjetivo dos alunos, efetivável mediante tutela específica. NEGARAM PROVIMENTO A AMBOS OS RECURSOS E, EM REEXAME NECESSÁRIO, CONFIRMARAM A SENTENÇA. UNÂNIME. (Apelação Cível $\mathrm{N}^{\circ}$ 70009489964, Sétima Câmara Cível, Tribunal de Justiça do RS, Relator: Luiz Felipe Brasil Santos, Julgado em 10/11/2004).
\end{abstract}

Em que pese a regra contida no art. $5^{\circ}, \S 1^{\circ}$ da $\mathrm{CF}$, no sentido de que as normas que atribuem direitos e garantias fundamentais têm eficácia plena e imediata, há quem ainda sustente que a norma que estabelece o direito social à educação inseridos os programas suplementares de material didático-escolar, transporte, alimentação e assistência à saúde (CF, art. 208, VII) - seria de natureza programática, portanto, de eficácia limitada, condicionada à posterior regulamentação legal.

Entretanto, a Lei $n^{\circ}$ 10.709/03 trouxe a regulamentação, a explicitação que faltava, colocando definitivamente uma norma sobre a questão, ao consagrar a obrigação de estados e municípios em proverem o transporte dos alunos matriculados em seus respectivos estabelecimentos.

\title{
O PROGRAMA SUPLEMENTAR DO TRANSPORTE ESCOLAR
}

A Constituição Federal estabelece no inciso VII do art. 208, a importância do atendimento ao educando, no ensino fundamental, dos programas suplementares de material didático-escolar, transporte, alimentação e assistência à saúde. 
O transporte escolar possui caráter suplementar, uma vez que a família possui obrigação precípua em relação ao educando, e que não é só do Estado, mas também da família, dos pais ou responsáveis legais, a responsabilidade pelo desenvolvimento de ações que assegurem o direito à educação.

Nesse sentido, o transporte e a facilitação do acesso à escola não incumbe exclusivamente ao ente Público, a quem compete oferecer a linha de transporte escolar, mas também à família, que não está isenta de colaborar no transporte de sua criança ou adolescente, numa dimensão de co-responsabilidade.

É importante registrar que não existe disposição legal constitucional ou de Lei Federal que delimite o trajeto da linha de transporte ou a distância a ser percorrida pelo aluno até o ponto de passagem do veículo escolar. O trajeto do transporte, seus pontos de passagem e parada são definidos pelo Poder Público, o qual deve utilizar-se para tal fixação dos critérios de bom senso, razoabilidade e viabilidade, todos no ambiente do Princípio Constitucional da Eficiência.

O trajeto a ser percorrido pelos alunos até o ponto de embarque no transporte escolar, tem gerado controvérsias em várias localidades rurais devidos as suas distâncias e condições dos acessos, sendo objeto de questionamento no Poder Judiciário, o qual tem se manifestado ao indicar ao Executivo o dever de analisar, dentro do seu planejamento estratégico, com bom senso, a forma de fixar o percurso do transporte escolar.

Algumas decisões do Poder Judiciário sobre o tema reafirmam a responsabilidade da família no transporte do aluno quando a residência e a escola forem próximas :

Não há dúvida de que a Constituição da República atribui ao Estado o encargo de assegurar a educação a todos. Isto significa que deve ser dado o acesso a ela, inclusive através do transporte. Tais enunciados estão devidamente indicados e transcritos nas razões das partes. Todavia, como se vê, daí não se pode interpretar que a obrigação do Estado é apanhar todas as crianças nas suas casas e conduzi-las até cada uma das escolas. É preciso que ofereça educação e meios para que se tenha a ela acesso, tão somente. Vale dizer, escola e transporte. Mas, havendo escola e acesso a ela pela proximidade razoável em que se encontra localizada em relação à residência do aluno, é claro que não se pode exigir transporte. Seria, como já se disse muitas vezes, atribuir ao Estado obrigações inexequiíveis, diante da realidade, e ao Poder Judiciário a capacidade de resolver todos os problemas com provimentos judiciais. Claro que se compreende a aflição dos pais e, no caso, da mãe que já sofre com a própria deficiência apresentada pela filha e luta para que nada lhe falte e possa compensar o "déficit" que apresenta. Entretanto, como ficou demonstrado, há escola especial distante da casa da autora 800 metros. Ora, 
considerando que a autora não tem nenhuma limitação quanto à capacidade locomotora, embora tenha apenas 12 anos de idade, a distância não é demasiada, a ponto de ser necessário transporte. Estas considerações foram feitas na sentença recorrida que, a meu ver, está correta. (Apelação Cível n. ${ }^{\circ} 598549764$ - TJRS ,Rel. Des. Perciano de Castilhos Bertoluci).

No mesmo sentido, uma outra decisão de Tribunal :

Notadamente, o itinerário do ônibus escolar fica inteiramente submisso ao interesse público, traduzido este através da administração municipal. Ela é que, melhor do que ninguém, tem condições de definir roteiro do ônibus, atendendo, p.ex., maior número de interessados.

No caso, questiona a inicial a modificação do trajeto, o que implicou na necessidade de os filhos do autor terem de se deslocar por mais de $4 \mathrm{~km}$. Ora, então, cabe aos pais, também responsáveis pela educação, na forma do art. 208, $\mathrm{CF} / 88$, levar os filhos até local próximo ao novo trajeto. Mas, de forma alguma podem eles pretender que a coletividade tenha de se submeter à sua conveniência ou comodidade. (Apelação Cível n. ${ }^{\circ} 597179076$ - TJRS, Des. Armínio José Abreu Lima da Rosa).

AGRAVO DE INSTRUMENTO. ESTATUTO DA CRIANÇA E DO ADOLESCENTE. AÇÃO CIVIL PÚBLICA. TRANSPORTE ESCOLAR. MUNICÍPIO DE CRISTAL. ALUNOS RESIDENTES EM ZONA RURAL. O art. $1^{\circ}$, $3^{\circ}$, da Lei $n^{\circ} 8.437 / 92$ veda a concessão de medida liminar que esgote, no todo ou em qualquer parte, o objeto da ação. Ressentindo-se o feito, neste momento processual, de elementos suficientes a amparar o pedido liminar e levando-se em consideração que o transporte escolar é fornecido pelo município às crianças que dele necessitam, em cumprimento aos dispositivos constitucionais e infraconstitucionais que regulam a matéria, há necessidade, por ora, de cooperação da família, a fim de incentivar e implementar o acesso ao ensino, o que pode se dar pela condução das crianças, pelos pais ou responsáveis, até a parada de ônibus mais próxima. DECISÃO MONOCRÁTICA. RECURSO DESPROVIDO. (Agravo de Instrumento $N^{\circ}$ 70012962114, Oitava Câmara Cível, Tribunal de Justiça do RS, Relator: José Ataídes Siqueira Trindade, Julgado em 18/11/2005)

Em suas razões de voto, o Des. Relator justificou:

Embora a educação seja direito constitucionalmente assegurado, não se pode desconsiderar que, nos termos da Lei de Diretrizes e Bases da Educação Nacional (Lei no 9.394/96), ela é "dever da família e do Estado, inspirada nos princípios de liberdade e nos ideais de solidariedade humana, tem por finalidade o pleno desenvolvimento do educando, seu preparo para o exercício da cidadania e sua qualificação para o trabalho" (art. $2^{\circ}$ ).

Vale dizer que há necessidade de cooperação mútua entre a família e o ente público, a fim de incentivar e implementar o acesso ao ensino.

Sobre a fixação do trajeto ou itinerário do veículo, encontra-se decisão favorável ao Município, no sentido da discricionariedade da Administração Pública em tal definição:

Mandado de segurança. Transporte Escolar. Campinas do Sul. "Mandamus" visando a restabelecer itinerário anterior. Inviabilidade. Matéria de fato. Ausência de direito líquido e certo a itinerários. Discrição do administrador. Questão a ser 
discutida em ação própria e não em mandado de segurança. Apelo provido. Reexame prejudicado

O que se pretende com a garantia ao transporte escolar é permitir o acesso dos alunos ao ensino. No entanto, essa garantia não impõe ao Município a obrigação de deslocar o veículo escolar até a porta da residência de cada aluno; há que se considerar, em nome do princípio da razoabilidade, a co-responsabilidade dos pais na educação dos filhos, providenciando o mínimo que seja de seu deslocamento.

Ao Município não incumbe, exclusivamente, toda a responsabilidade pelo transporte do educando, havendo a necessidade de cooperação por parte da família, sendo que a definição do trajeto é ato discricionário da Administração, a qual deverá encontrar fundamento em critérios de possibilidade, necessidade e razoabilidade.

\section{PRINCIPIO DA EFICIÊNCIA E A EFETIVIDADE DOS SERVIÇOS}

A Administração Pública é um corpo estruturado para que o Estado possa concretizar os seus objetivos para os quais foi criado, designa tanto a estruturação dos órgãos, os serviços do Estado, a sua composição por agentes e as suas atividades essenciais.

Segundo Ferreira Filho (2000, p.219) “O poder executivo compreende o governo, que é sua cabeça, e a administração, que consiste em seu tronco e membros". Para isso existem os três Poderes, compostos por vários órgãos, cada um com uma determinada finalidade a cumprir, mas todos integrados e harmônicos, visando à satisfação do interesse público.

Como ressalta Di Pietro (2005, p. 34) “os princípios são primordiais no Direito Administrativo, os princípios funcionam na base de um sistema, servindo como instrumentos orientadores, que levam a compreensão exata do ordenamento".

Os princípios são normas dotadas de positividade, que determinam condutas obrigatórias impedindo a adoção de comportamento com eles incompatível. Servem para orientar a correta interpretação das normas isoladas, indicar, dentre as interpretações possíveis diante do caso concreto, qual deve ser obrigatoriamente adotada pelo aplicador da norma, em face dos valores consagrados pelo sistema jurídico.

Segundo o conceito de Cretella Júnior (2005, p.222), "princípios de uma ciência são as proposições básicas, fundamentais, típicas que condicionam todas as estruturações subsequentes". Princípios, neste sentido, são os alicerces da ciência, 
possuem função programática, fornece diretrizes situadas no ápice do sistema a serem seguidas por todos aplicadores do direito.

Os princípios se constituem mutuamente e não se excluem no conjunto de interpretação do ordenamento jurídico, sendo os princípios norteadores da administração Pública Brasileira os seguintes: princípio da legalidade, princípio da impessoalidade, princípio da moralidade, princípio da publicidade e princípio da eficiência, conforme destaca a Constituição Federal :

Art. 37. A administração pública direta e indireta de qualquer dos Poderes da União, dos Estados, do Distrito Federal e dos Municípios obedecerá aos princípios de legalidade, impessoalidade, moralidade, publicidade e eficiência e, também, ao seguinte: (gn)

\section{(...) omissis}

A Legalidade traduz a idéia de que a Administração Pública não tem liberdade e nem vontade pessoal, só pode fazer o disposto em lei; o princípio da impessoalidade, atividade administrativa deve ser dirigida com finalidade pública, aos cidadãos em geral, sem favoritismos e discriminações; já o Princípio da Moralidade, impõe a Administração não apenas uma atuação legal, mas também moral, pautada na ética, honestidade, lealdade, boa fé e o princípio da publicidade, visa garantir o controle através da sociedade da gestão administrativa.

O Princípio da Eficiência impõe à Administração Pública direta e indireta a obrigação de realizar suas atribuições com rapidez, qualidade, efetividade, perfeição e rendimento - isto porque a atividade estatal produz de modo direto ou indireto consequências jurídicas que instituem, reciprocamente, direito ou prerrogativas - ou obrigações para a população, traduzindo uma relação jurídica ente a Administração e os administrados.

A Emenda Constitucional nº 19/1998 tornou expresso esse princípio a ser observado pela Administração Pública Brasileira, seja direta ou indireta, presente no caput do artigo 37 da Constituição Federal. Todavia menciona Moraes (2004, p. 33) que "tal princípio já existia na legislação infraconstitucional, a exemplo do Decreto-lei 200/67, da Lei no 8.987/95 das Concessões e Permissões e do Código de Defesa do Consumidor". 
A Eficiência é representada pelo dever da boa administração, pressupõe a realização das atribuições com máxima presteza, rapidez e prontidão, com qualidade perfeita e de forma tanto qualitativa como quantitativamente.

O Princípio da Eficiência possui o condão de gerar mudanças no comportamento funcional da Administração, o artigo 39, § 7o, da C.F/88, dispõe que a União, Estados, Distrito Federal e Municípios disciplinarão a aplicação de recursos orçamentários provenientes da economia com despesas correntes em cada órgão para aplicação no desenvolvimento de programas de qualidade e produtividade, treinamento e desenvolvimento, modernização, reaparelhamento e racionalização do serviço público, inclusive sob a forma de adicional ou prêmio de produtividade.

Assim, o inciso VII do art. 208 deve ser observado e cumprido pele ente Público em consonância com o Principio da Eficiência, contido no caput do art. 37 ambos da Constituição Federal, buscando o bem servir pois a sua efetividade garante o acesso a escola dos educandos e evita o êxodo rural.

\section{O TRANSPORTE ESCOLAR NA ZONA RURAL DA CIDADE DE MANAUS}

A Cidade de Manaus possui 85 escolas na divisão distrital da Zonal Rural, sendo subdividida por áreas: 35 Rodoviárias (AM-010, BR-174, Puraquequara e Tarumã) e 50 Ribeirinhas (21 no Rio Amazonas e 29 no Rio Negro), e conta com 50 lanchas, 66 ônibus e 68 micro-ônibus para fazer a condução dos alunos da zona Rural de Manaus.

A região norte apresenta peculiaridades que são os rios e igarapés, com isso as escolas do campo recebem, ao mesmo tempo, alunos que são transportados por lancha e por ônibus, além de estarem sujeitas ao regimes diferenciados de calendário escolar, conforme prevê a Lei de Diretrizes e Bases da Educação (Art. 23, § $2^{\circ}$ e Art. 24, inciso I da Lei n. 9394/96).

A referida norma autoriza que por fatores climáticos, o calendário escolar seja alterado, sendo disciplinado nas escolas do campo da cidade de Manaus pela resolução no 034/CME/2016, aprovada em 01.12.2016, que trata do Calendários da Rede Pública Municipal de Ensino do ano letivo de 2017, das escolas do campo, divididos, em Calendário Escolar 2017 da Educação Infantil e fundamental da Zona 
Rural Ribeirinha - Rio Negro e - Calendário Escolar 2017 do Ensino infantil e Fundamental da Zona Urbana / Rural Rodoviária e Ribeirinha - Rio Amazonas.

O Calendário diferenciado é distribuído da seguinte forma: as aulas para 2,3 mil estudantes de 29 escolas municipais de Manaus, localizadas em comunidades do Rio Negro, iniciaram no dia 6 de janeiro, e para 1,7 mil estudantes de 21 escolas municipais de Manaus, localizadas em comunidades do Rio Amazonas, iniciaram no dia 1 de fevereiro.

O fator determinante para a existência de dois calendários escolares para as escolas da zona rural da cidade de Manaus, reside no fato de que na região norte o regime de chuvas e dos rios, cheia e seca, dificultam o acesso às escolas e impossibilita que os alunos e Professores cheguem com segurança às mesmas.

\section{O PLANEJAMENTO DO TRANSPORTE ESCOLAR RURAL}

A questão fundamental para o transporte escolar rural é o planejamento das ações para que o serviço seja executado com eficiência e atenda a toda a comunidade de modo universal, pois o que torna uma escola acessível, nesse sentido, não é a quantidade de vagas, mas a possibilidade das crianças chegarem à mesma.

A realidade da região amazônica resulta no fato de que, estar distante de um centro urbano torna mais difícil essa missão, em especial em função da infraestrutura das estradas e dos veículos de transporte em regiões afastadas, quando se considera toda a trajetória e as dificuldades que muitas vezes estes estudantes e docentes da área rural têm em chegar à sala de aula devida à distância da escola de suas residências.

No planejamento da prestação do serviço de transporte escolar rural deve ser analisado vários aspectos para que este não seja um fator de êxodo escolar ou de interferir na qualidade fisica e mental do aluno em sala de aula e, assim, tornar possível o acesso a escola com segurança e regularidade.

Um conjunto de ações devem ser estruturados para a eficiência do serviço, como a compatibilidade do meio com o objeto; ou seja, adequação dos veículos com as características físicas do passageiro do transporte escolar rural, a continuidade na oferta do serviço do transporte escolar rural, sem interrupção, cumprimento do itinerário, disponibilidade espacial do serviço com a existência de uma ligação entre 
o local de residência do aluno e a escola em que estuda e a oferta do serviço do Transporte Escolar Rural nos dias e horários em que o aluno necessita.

Além desses aspectos o mais importante de todos é o tempo; ou seja, o tempo de acesso ao ponto de parada, o tempo que o aluno leva para percorrer a distância entre o local de sua residência e o ponto de embarque no transporte, ou a distância entre o ponto de desembarque do transporte e a escola, o tempo de viagem no veículo, tempo que o aluno permanece no veículo escolar durante o trajeto casa-escola ou escola-casa e o tempo de transbordo, tempo de desembarque, deslocamento, espera e embarque, nos casos em que o aluno troca de veículo e a pontualidade.

O Principio da Eficiência deve nortear todos os aspectos dos serviços de transporte escolar rural, especialmente na qualidade com que este serviço é realizado para que não se torne um desserviço e assim contribuir para a não desistência escolar e não interferindo na saúde fisica ou mentalmente do educando, prejudicando-o no regimento escolar dos alunos da zona rural.

\section{CONCLUSÃO}

O objetivo desta pesquisa foi o de analisar a legislação brasielira, no tocanto ao trasnporte escolar urbano para verificar se havia dispositivo legal que permitisse enfrentar o problema da pesquisa que se traduz na necessidade de assegurar aos estudantes da zona rural do municipio de Manaus/AM, o direito ao acesso à escola e, consquetemente o de aprendizado, durante todos os períodos do ano de forma que essas crianças não se prejudicassem e sofressem o abandono intelectual.

A conclusão a que se chegou é de que esse direito à educação está expresso na Constituição Federal (art. 228), que a assegura, também, como um direito social $\left(\operatorname{art.} 6^{\circ}\right)$.

Esse direito também é assegurado pela Lei de Diretrizes e Bases da Educação (LDB - Lei n ${ }^{\circ}$ 9.394/1996), que ratifica os pressupostos estabelecidos pela Constituição Federal no sentido de impor ao Estado, o provimento de Programas Educacionais que proporcione ensino obrigatório e gratuito, inclusive para pessoas com defasagem idade-série, bem como o fornecimento de assistência social, alimentação, transportes e material didático. 
Assim, o Poder Público tem o dever de garantir o acesso e a permanência dos alunos da rede pública nas unidades de ensino rurais, devendo planejar, ofertar e executar o transporte escolar rural a fim de garantir que o mesmo atenda às necessidades dos estudantes, com qualidade e eficiência, combatendo por via reflexa, o êxodo rural e a evasão escolar.

O transporte rural é um dever suplementar do Poder Público, como medida para amenizar a segregação sofrida no campo, viabilizando uma maior integração entre o meio rural e urbano e para atender às necessidades que os estudantes residentes da zona rural têm de acessar a escola.

$\mathrm{Na}$ zona rural da cidade de Manaus, o fator climático determina a existência de dois calendários escolares, pois o regime de chuva e dos rios é um fator que dificulta o acesso às escolas dado as dificuldades de infraestrutura da região, sendo comum, em determinadas épocas do ano, as escolas do campo ficarem isoladas.

Cuidar da população rural do Brasil é uma decisão estratégica, fixar o homem do campo vai além de oferecer assistência técnica e extensão rural: o Estado Brasileiro deve fomentar um conjunto de ações públicas objetivando atender a qualidade de vida das famílias do campo, dentre elas a de priorizar o acesso a escola, pois se a família do agricultor não tem condiações mínimas de se manter no campo, o êxodo rural se torna uma alternativa a ser considerada. Dessa forma, quem, perde seria o homem do campo e o homem urbano, pois este ultimo não produz alimentos para sua sobrevivência digna.

Assim, o resultado desta pesquisa é o de que existe mandamento constitucional e infraconstitucional suficientes para obrigar e resposnabilziar o Poder Público no tocante a construção e execução de Políticas Públicas eficazes de transporte escolar rural.

\section{REFERÊNCIAS}

BARROS, Jussara de. Transporte Escolar; Brasil Escola. Disponível em <http://brasilescola.uol.com.br/educacao/transporte-escolar-1.htm>. Acesso em 15 de abril de 2017. 
BARROSO, Luís Roberto. Curso de Direito Constitucional Contemporâneo: os conceitos fundamentais e a construção do novo modelo. São Paulo: Saraiva, 2009. Neoconstitucionalismo e Constitucionalização do Direito. (O Triunfo

Tardio do Direito Constitucional no Brasil). [Revista Eletrônica sobre a Reforma do Estado] (RERE). Salvador, Instituto Brasileiro de Direito Público, n. 9. Março/abril/maio, 2007. http://www.direitodoestado.comcom.br/redae.asp. Acesso 20/11/2016.

BRASIL.Constituição da República Federativa do. Congresso Nacional, Brasília, 1988.

Código Civil. Lei 10.406. Congresso Nacional, Brasília. 2002.

. Emenda Constitucional no 19, de 04 de junho de 1998. Congresso Nacional, Vbrasilia, 1998.

. Estatuto da Criança e do Adolescente: Lei $n^{0}$ 8.069/90, Congresso Nacional, Brasília. 1990.

Lei de Diretrizes e Bases da Educação: Lei Federal $n^{0}$ 9.394/96. Congresso Nacional, Brasília. 1996

Lei de Diretrizes e Bases da Educação: Lei Federal 10.709/03, Congresso Nacional, Brasília. 2003.

COMPARATO, Fábio Konder. Fundamento dos Direitos Humanos. Instituto de Estudos Avançados da Universidade de São Paulo. São Paulo: 1997. Texto disponível $<$ http://www.iea.usp.br/publicacoes/textos/comparatofundamento.pdf/view>. Acesso: 14 abr 2017.

CONVENÇÃo AMERICANA De DIREITOS HUMANOS. Pacto de San José da Costa Rica. Organização dos Estados Americanos [OEA], 1969.

CRETElla JUNIOR, José. Primeiras lições de direito. Rio de Janeiro: Forense, 2005.

DINIZ, Maria Helena. Curso de Direito Civil Brasileiro. São Paulo: Saraiva, 2007. DI PIETRO, Maria Sylvia Zanella. Direito Administrativo. São Paulo: Atlas, 2005. FERREIRA FILHO, Manuel Goncalves. Curso de Direito Constitucional. São Paulo: Saraiva, 2000. 
GADOTTI, Moacir. Pedagogia da Terra. Serie Brasil cidadão. São Paulo, Peirópolis, 2000.

GASPARINI, Diógenes. Direito Administrativo. Editora Saraiva, São Paulo, 2005, pág. 21.

MANAUS, Secretaria Municipal da cidade de. Disponivel em http://www.semed.manaus.am.gov.br consultada em 20 abr 2017.

,Resolução n. 34. Conselho Municipal de Educação. Prefeitura Municipal de Manaus 2016.

MEIRELLES, Hely Lopes. Direito Administrativo Brasileiro. Malheiros Editores 2004.

MELlO, Celso Antônio Bandeira. Curso de direito administrativo. São Paulo: Malheiros, 2005.

MENDES, Gilmar Ferreira; COELHO, Inocêncio Mártires; BRANCO, Paulo Gustavo Gonet. Curso de direito constitucional. São Paulo: Saraiva, 2009.

MORAES, A. de. Direito constitucional. São Paulo: Atlas, 2004.

SILVA, José Afonso da. Direito Constitucional Positivo. São Paulo: Malheiros, 2004. 